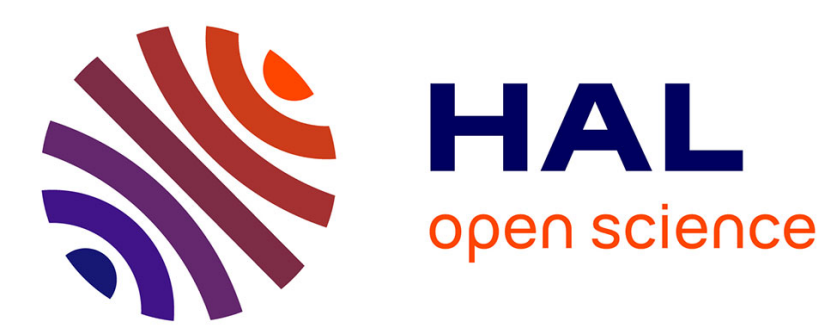

\title{
Fire behavior of simulated low voltage intumescent cables with and without electric current
}

\author{
Johan Sarazin, Pierre Bachelet, Serge Bourbigot
}

\section{To cite this version:}

Johan Sarazin, Pierre Bachelet, Serge Bourbigot. Fire behavior of simulated low voltage intumescent cables with and without electric current. Journal of Fire Sciences, 2017, 35 (3), pp.179 - 194. 10.1177/0734904117698843 . hal-01697376

\section{HAL Id: hal-01697376 https://hal.science/hal-01697376}

Submitted on 31 Jan 2018

HAL is a multi-disciplinary open access archive for the deposit and dissemination of scientific research documents, whether they are published or not. The documents may come from teaching and research institutions in France or abroad, or from public or private research centers.
L'archive ouverte pluridisciplinaire HAL, est destinée au dépôt et à la diffusion de documents scientifiques de niveau recherche, publiés ou non, émanant des établissements d'enseignement et de recherche français ou étrangers, des laboratoires publics ou privés. 


\title{
Fire behavior of simulated low voltage intumescent cables with and without electric current
}

Journal of Fire Sciences

Volume: 35 issue: 3, page(s): 179-194

Authors:

Johan Sarazin, Pierre Bachelet, Serge Bourbigot

$\mathrm{R}_{2}$ Fire Group/UMET-UMR CNRS 8207, Ecole Nationale Supérieure de Chimie de Lille (ENSCL), Villeneuve d'Ascq, France

Corresponding Author: Serge Bourbigot, $\mathrm{R}_{2}$ Fire Group/UMET-UMR CNRS 8207, Ecole Nationale Supérieure de Chimie de Lille (ENSCL), Avenue Dimitri Mendeleïev-Bât. C7a, CS 90108, 59652 Villeneuve d'Ascq, France. Email: serge.bourbigot@ensc-lille.fr

First published: 20/03/2017

DOI: $\underline{10.1177 / 0734904117698843}$

\begin{abstract}
.
Many circumstances can lead to an electrical fire. It is then helpful to reproduce those circumstances in laboratory conditions to duplicate fire scenarios in order to increase knowledge and to develop safer and flame-retarded materials and electrical systems. Our approach was to develop specific bench scale tests. The mass loss cone calorimeter coupled with Fourier transform infrared was used to mimic a fire scenario on simulated low voltage cable (flame-retarded polymer molded around copper wire) and to characterize the gas phase. The electric current creates an additional heating condition (Joule effect) which can modify the decomposition of the flammable material (e.g. the cable jacket made in thermoplastic), and so its fire behavior in case of fire. It is the reason why we performed the experiments mimicking different fire scenarios with and without electric current. Specific test was also developed to investigate the flame spread and the delamination of the polymer around the wire. The bench scale tests presented in this article were applied on intumescent polymers (ethylene-vinyl acetate containing commercial intumescent additive). The results were discussed with a special emphasis on the influence of electric current on the fire behavior.
\end{abstract}

\section{Keywords}

Cable, electric current, intumescence, EVA 


\section{Introduction}

According to a recent NFPA report of $2013,{ }^{1}$ an estimated 47,700 home structure fires reported to US fire departments in 2011 involved electrical failure or malfunction as a factor contributing to ignition. These fires resulted in 418 civilian deaths, 1570 civilian injuries, and US\$1.4 billion in direct property damage. Non-home electrical fires in 2011 were estimated at 16,400, with associated losses of 13 civilian deaths, 243 civilian injuries, and US\$501 million in direct property damage. The most inclusive and direct interpretation of "electrical fire" is a fire involving some type of electrical failure or malfunction. Any equipment powered by electricity can have such a failure. Polymeric materials are very often involved in such fires and so it is paramount to investigate their fire behavior in those conditions. Among them, electrical cables are potential combustible materials which can spread fire along cable trays.

The electrical cables are used in different fields, with different requirements and different environments. Many circumstances can lead to the degradation of the insulation system of an electrical cable. The insulation sheath to electrical cables can be ignited by an external source; however, according to the power supply, the applied electric field, the composition of the conductor and of the insulative material, different failures can occur such as a short-circuit, heating, sparks, or electrical arcing. ${ }^{2,3}$

The short circuits can come from an unfortunate human action (punching of a cable), an avalanche failure mechanism, or birth of electrical tree. The avalanche failure mechanism is caused by an electron initially injected to the cathode. The electron is accelerated toward the anode under the influence of an electric field and receives sufficient energy to release another electron by ionization. If the mechanism continues, the local concentration of high energy electron increases, creating a conductive road between the electrodes. The birth of electrical tree is caused by an internal electrical discharge, locally destroying the material by forming very fine channels. In short, medium, or long term, this mechanism will lead to electrical breakdown that is a consequence of the formation of a conductive path.

Additional heating can be generated by the Joule effect, which can be due to a partial disconnection, an overcurrent, or by a relaxation phenomenon under alternative current. Electrical arcs can come from a reduction of the dielectric properties of the sheathing, the presence of moisture and/or a conductive dust deposit or of an overvoltage. This additional heating of the conductor caused by Joule effect can modify the fire behavior of the material, but it is not taken into account in conventional tests (ISO5660, EN50399). Hence, it makes sense to reproduce this additional heating in laboratory conditions to investigate the modification of the fire behavior of the formulation used for insulation sheath. It should increase our understanding and should permit to develop safer and flame-retarded materials for electrical systems.

In recent years, concerns have been widely expressed about the inherent toxicity of halogenated flame retardants used for decades in electrical and electronics applications. If these formulations limit the spread of fire, they significantly hinder the rescuers because of the opacity of smoke released and cause extensive damage due to the presence of corrosive vapors. ${ }^{4}$ These factors lead to an increasing demand of non-halogenated flame retardants in electrical and electronics applications. Thus, phosphorus derivatives are more and more used in polymeric materials thanks to their high efficiency and their reasonable loading. In addition, they are widely used in intumescent systems. 
In this article, a small scale test developed in our $\operatorname{lab}^{5}$ and a mass loss calorimeter (MLC) coupled with a Fourier transform infrared (FTIR) spectrometer were used for the evaluation and characterization of cables. In order to test our own materials developed in the laboratory, an experimental protocol to prepare "homemade cable" was set up. It permits to mimic the fire behavior of real low voltage cables. The simulated cables are constituted of an external cable jacket composed of intumescent ethylene-vinyl acetate (EVA) copolymer molded around a copper wire.

The bench scale test results are presented in the first section of the article. In the second section, simulated cables are evaluated according to the above test. The results are presented and discussed with a special emphasis on the influence of electric current on the fire behavior.

\section{Experimental: materials and bench scale test}

\section{Materials}

EVA copolymer containing $28 \mathrm{wt} \%$ of vinyl acetate (EVA) was supplied by Arkema. Exolit AP 760 is a non-halogenated flame retardant (FR) based on ammonium polyphosphate (APP); Exolit AP760 in white powder was supplied by Clariant. When incorporated within a polyolefin, this compound develops an intumescence phenomenon when a heat source is applied. ${ }^{6}$ AP760 develops its effectiveness through phosphorus/nitrogen synergism. The concept of intumescence relies upon the formation of an expanded carbonized layer on the surface of the polymer during thermal degradation. This layer acts as an insulating barrier limiting heat and mass transfers in the material. ${ }^{7}$ Two formulations were evaluated: (1) $20 \mathrm{wt} \%$ and (2) 30wt\% of AP760 were incorporated into EVA. Those formulations were prepared using a Brabender mixer $350 / \mathrm{EH}$ at a shear rate of $50 \mathrm{r} / \mathrm{min}$ and at $180^{\circ} \mathrm{C}$. EVA was melted for $5 \mathrm{~min}$, afterward AP760 (20wt\% or 30wt\%) was incorporated in EVA and the formulation was mixed for $15 \mathrm{~min}$ (total duration of $20 \mathrm{~min}$ ). Virgin EVA and the two FR formulations are molded around a copper wire using a hot press according to the protocol described in Figure 1. Two molds were used, a first one of $520 \times 100 \times 3 \mathrm{~mm}^{3}$ to make cables which will be tested on the bench scale test and the other one of $100 \times 100 \times 3 \mathrm{~mm}^{3}$ to make a plate containing conductors which will be tested at MLC (Figure 2). The simulated cables were manufactured using a hydraulic press. In both cases, the principle is the same: the conductors are placed in a guide and attached to a tensioner mechanism to obtain a fully extended set of parallel wires. Then, the formulation is placed into the mold and is thermoformed in the press $\left(180^{\circ} \mathrm{C}\right.$ for pure EVA and $200^{\circ} \mathrm{C}$ for formulations containing AP760).

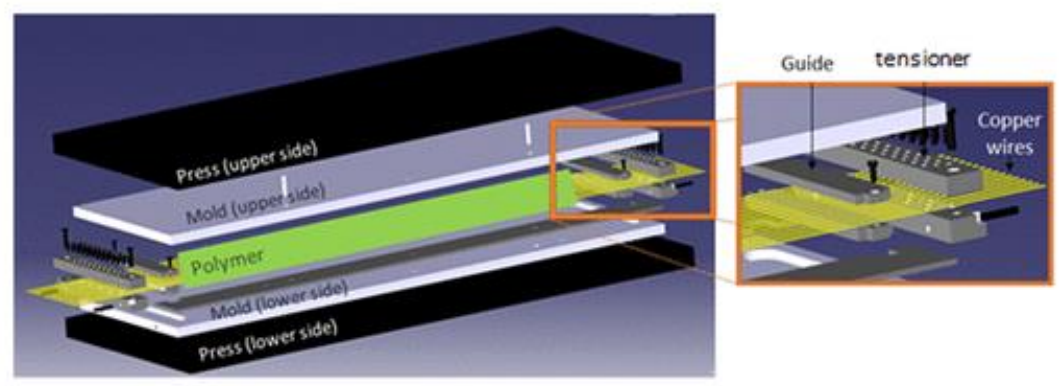

\section{Figure 1.}

Experimental protocol to make simulated cables. 

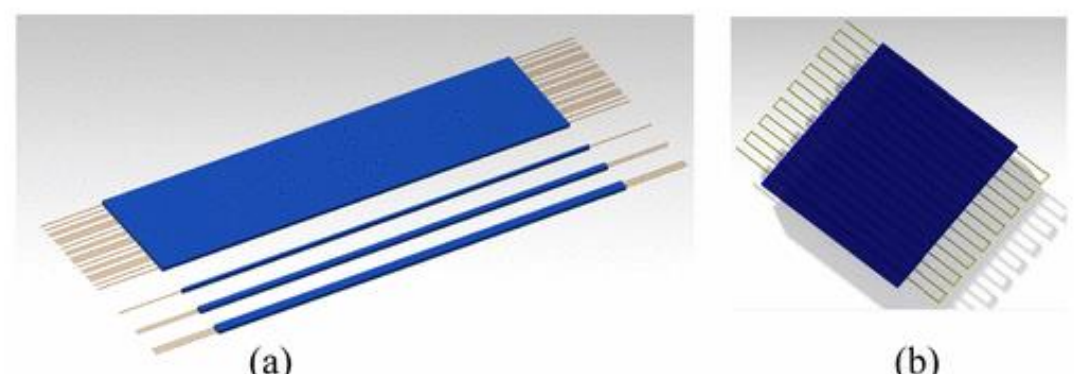

(b)

\section{Figure 2.}

(a) Molded cables and (b) molded plate containing wires for MLC
experiments.

\section{Mass loss cone coupled with FTIR}

MLC (Fire Testing Technology) coupled with FTIR Spectrometer were used to characterize the gas phase of samples upon burning. The experiments were performed according to the procedure defined in ASTM E 906 (except FTIR, which is not included in the standard). The equipment is identical to that used in oxygen consumption cone calorimetry (ASTM E-135490), except that a thermopile in the chimney is used to obtain heat release rate (HRR) rather than employing the oxygen consumption principle. Our procedure involved exposing plates in horizontal orientation. Samples were placed on a ceramic backing board at a distance of $25 \mathrm{~mm}$ from cone base. The external heat flux was of $35 \mathrm{~kW} / \mathrm{m}^{2}$ and the experiments were performed with piloted ignition and by submitting or not the sample to an electric current of $32 \mathrm{~A}$. MLC was used to determine the following main fire properties: HRR as a function of time, peak of heat release rate (pHRR), time to ignition (TTI), and total heat release (THR). When measured at $35 \mathrm{~kW} / \mathrm{m}^{2}, \mathrm{HRR}$, THR, and TTI values are reproducible to within $\pm 10 \%$. Experiments were performed in triplicate to ensure repeatability of results. To investigate the gases released during MLC experiment, MLC was connected to a Fourier transform infrared spectrometer (MLCFTIR).

Referring to previous work, gas phase FTIR spectroscopy has the potential to measure almost all volatiles on a continuous basis during fire. ${ }^{\underline{8}, \underline{9}}$ The calibrated FTIR spectrometer used is from Thermo Scientific ${ }^{\mathrm{TM}}$ (Antaris ${ }^{\mathrm{TM}}$ industrial gas system (IGS) equipped with a gas cell with an optical pathway of $2 \mathrm{~m}$ long). Temperature and pressure must be taken into account in order to obtain accurate and repeatable results. Numerous studies report the influence of temperature and pressure on infrared absorption spectra. ${ }^{9}$ Here, the gas cell is maintained at $185^{\circ} \mathrm{C}$ and the pressure inside the cell is set to 652 torr. Gas picking pistol and transfer line were provided by $M \& C^{\circledR}$ Tech Group. The transfer line between MLC and FTIR is $2 \mathrm{~m}$ long and was heated at a constant temperature of $180^{\circ} \mathrm{C}$ to avoid condensation in the transfer line. It has been shown that the optimum set temperature for this kind of sampling and analysis is $180^{\circ} \mathrm{C} .{ }^{10}$ Furthermore, this temperature is less than the gas cell temperature to avoid condensation in the gas cell. To get constant transfer line temperature, two temperature controllers were installed. Before analyzing the gases by FTIR, soot particles were filtered off by two different heated filters ( 2 and $0.1 \mu \mathrm{m}$ ). Filters consist of glass fibers and ceramic, respectively. The gases are analyzed online quantitatively and qualitatively with OMNIC software. The methodology of quantification has been developed in the laboratory, and the quantification is then performed using TQ Analyst software. Spectra have to be recorded at different concentrations of specific 
gases with the same conditions such as a cell temperature of $185^{\circ} \mathrm{C}$, a pressure of 652 torr, an optical path length of $2 \mathrm{~m}$, and the spectral range from 650 to $4500 \mathrm{~cm}^{-1}$. Then the area under the peaks of characterized absorbance bands is linked with the concentration of release gases. For it, representative spectral region has been chosen for each gas to minimize interferences with other gases to create a method, and representative regions in the spectra of the selected gas have to be chosen and interactions with other gases have to be taken into account. Using MLCFTIR, the following gases can be quantified: water, carbon monoxide, carbon dioxide, acetic acid, methane, and ethane. Quantification is reproducible within $\pm 10 \%$. MLC-FTIR experiments were performed twice to check the repeatability of the obtained results. The calibration was done by Thermo Scientific using the Fire Science Method and Calibration to analyze toxic gases in the combustion of building materials according to the standard ISO 19702:2006. The method can be used with cone calorimeters, smoke boxes, or ambient sampling of combustion experiments.

\section{Flame spread test}

All the existing standardized test measure flame spread of bundles of cable after ignition by a burner. The cables can be disposed in horizontal or vertical positions and are tested power down. Based on this, a small scale test was developed to study the fire behavior of a simulated cable with the possibility to work under voltage. The purpose is to investigate the influence of the electric current on the flame spread. Before developing a flame spread test, it is necessary to determine all possible scenarios involving an electrical cable in nominal operation or not. In the study, the conductor section used is $1.5 \mathrm{~mm}^{2}$. The first parameter to be examined is the intensity that can cross a $1.5-\mathrm{mm}^{2}$ cable. In nominal operation, a $1.5-\mathrm{mm}^{2}$ conductor is traversed by intensity as high as $16 \mathrm{~A}$. On a circuit with a non-adapted protection, the section of the conductor can be traversed by a higher current. In the worst cases, such as a bad connection or facility with inadequate protection, a cable with $1.5 \mathrm{~mm}^{2}$ conductor cross section may be connected to a system originally intended for a $6 \mathrm{~mm}^{2}$ (32 A). During a default, secondary security organs are the main differential circuit breaker to limit the current driven by the conductor. On some installations, the main GFCI (Ground Fault Circuit Interrupter) can reach a 65-A breaking intensity, which can induce intensity in a $1.5-\mathrm{mm}^{2}$ conductor up to four times its rated current. The second parameter to be examined in a fire scenario is the ignition occurring in relation to the electrical supply of the cable. The probable scenarios are ignition of the cable before, simultaneously or after powering on. The ignition of the cable after powering on is representative of fire safety cables. The ignition of the cable simultaneously with the electric power-up may correspond to a scenario where the cable is responsible for the fire. A fault in the electrical cable causes a sufficient dysfunction (significant heating, electric arc, and so on) to ignite the insulating sheath. The ignition of a cable after powering on is the most common case. There are two possibilities: the ignition of the insulation sheath is caused either by a dysfunction or by an external fire source. According to a preliminary study, it has been decided to perform the tests with a higher intensity than the nominal one as no significant differences in terms of fire behavior were observed when working at lower or equal intensity.

Also, it was required for the different tests to apply the intensity before starting the test and to wait for the stabilization of the system. In this work, a small scale test developed in the lab was used for the evaluation of the fire spread along the cables, without and with electric current, in horizontal or in vertical position. The description of the test is shown in Figure 3 with two different setups in horizontal and vertical positions. The burner is a Bunsen burner fed by $200 \mathrm{~mL} / \mathrm{min}$ of propane and delivering in those conditions a calibrated blue flame. The test is performed in natural convection under a hood without any extraction, with and without electric 
current (current of 32 or $60 \mathrm{~A}$ ). The measured parameters are as follows: flame spread rate (electric current of 0 and $32 \mathrm{~A}$ ) and time to delamination (electric current of $60 \mathrm{~A}$ ).

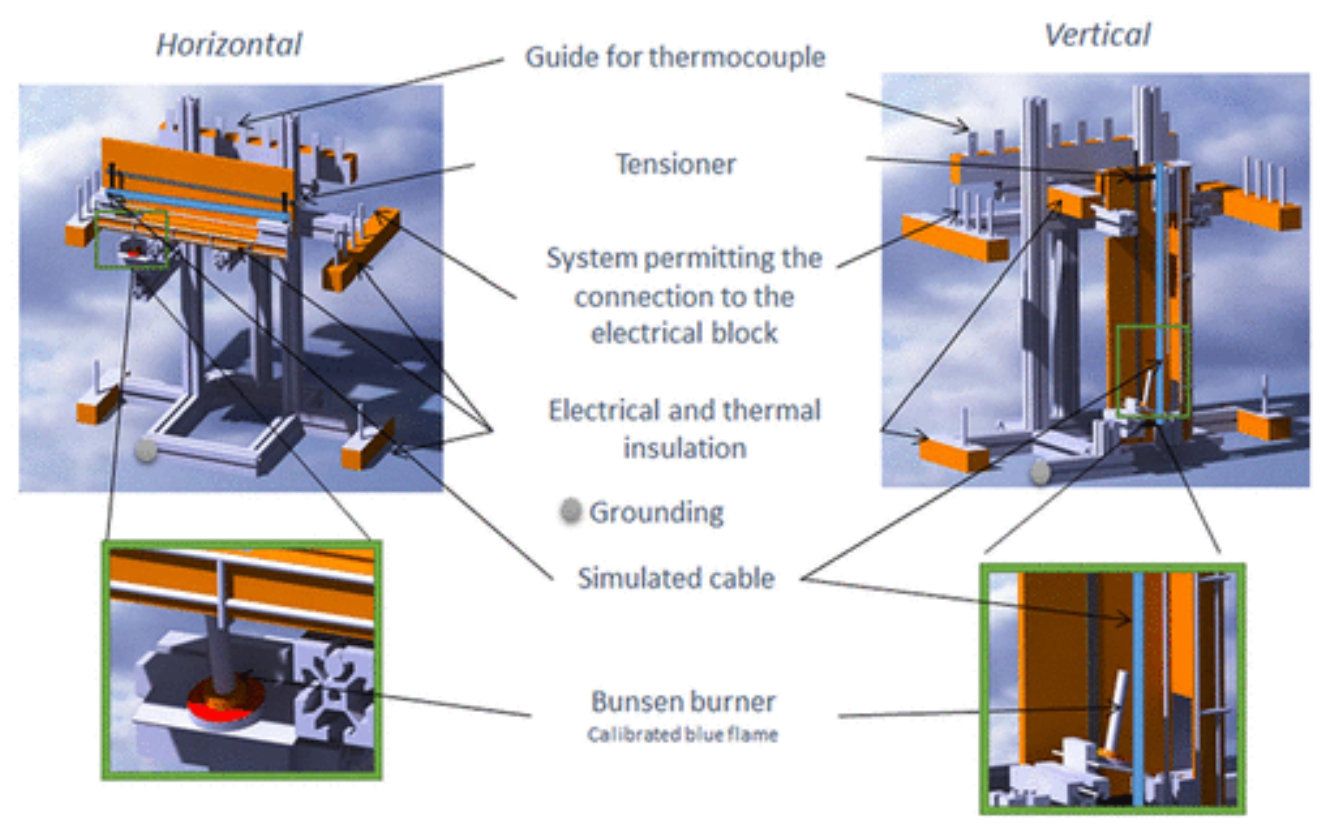

Figure 3.

Description of the flame spread test in horizontal and vertical positions.

\section{Results and discussion}

\section{Mass loss cone coupled with FTIR}

The concept of intumescence involves the formation of an expanded char at the surface of the polymer during thermal degradation. This char exhibits a multi-cellular structure and acts as an insulating barrier limiting heat and mass transfer. $\underline{11}, \underline{12}$

The intumescent formulations were first evaluated by mass loss calorimetry on plates containing or not copper wire to compare the conventional test (without conductor) with the test with electric current (with conductor). Note that no significant effect was detected on the material with and without copper wire (no electric current was applied) and it is not commented in the following. An electric current of $32 \mathrm{~A}$ is applied to the plate containing copper wire to evidence the effects of the current on the fire behavior of the formulations. In both cases, the incorporation of AP760 in EVA reduces dramatically the pHRR. The formulation filled with 20wt $\%$ AP760 exhibits a pHRR decrease by 54\% and that filled with 30wt\% AP760 exhibits $77 \%$ decrease of the pHRR (Figure 4). THR is decreased by $23 \%$ for the formulation filled with $30 \mathrm{wt} \%$ AP760 but no significant decrease is observed for the $20 \mathrm{wt} \%$ loaded formulation. 


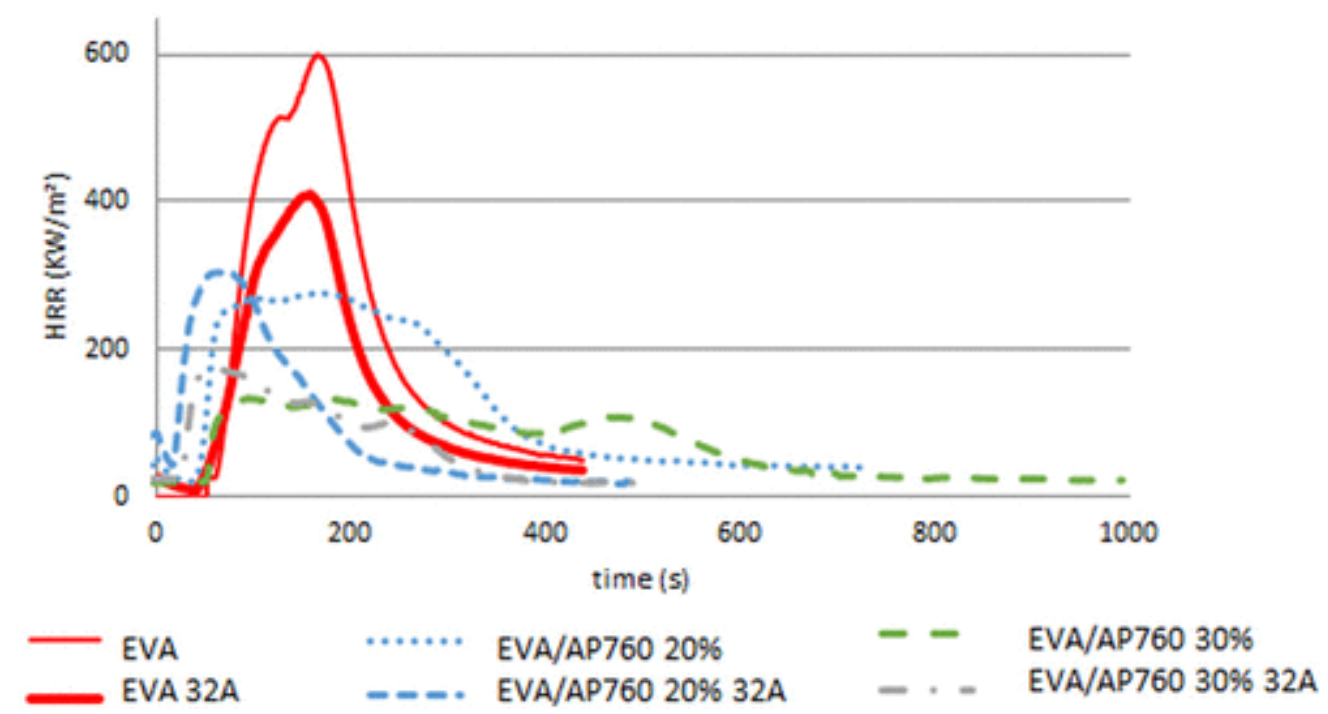

\section{Figure 4.}

HRR as a function of time of EVA and FR EVA with and without an electric current of 32 A with forced ignition (external heat flux $=35 \mathrm{~kW} / \mathrm{m}^{2}$ ).

When a current of $32 \mathrm{~A}$ is applied, two significant effects can be observed: diminution of the TTI and of the THR. The TTIs of the EVA and FR formulations are shorter when the current is on: TTI decreases from 60 to $41 \mathrm{~s}$ for neat EVA, from 43 to $20 \mathrm{~s}$ for $20 \mathrm{wt} \%$ AP 760 formulation, and from 53 to $31 \mathrm{~s}$ for $30 \mathrm{wt} \%$ AP760 formulation. This decrease can be explained by the fact that when power is on, the material undergoes an additional heating due to the Joule effect leading to a faster decomposition and therefore to a decrease of the TTI (assuming there is no change of the thermo-optical properties of the sample). The other effect of the current is the reduction of THR of neat EVA and of the two intumescent formulations. For the neat EVA, THR is reduced from 93 to $72 \mathrm{MJ} / \mathrm{m}^{2}$; at 20wt\% loading of AP760 in EVA, THR is reduced from 91 to $47 \mathrm{MJ} / \mathrm{m}^{2}$; and at 30wt\% loading in EVA, THR is reduced from 71 to $40 \mathrm{MJ} / \mathrm{m}^{2}$. It is an unexpected result (THR is decreased by about $45 \%$ for the intumescent materials) because it was reasonable to assume that an additional heating should lead to a faster and more complete decomposition of the materials. For the neat EVA, it is only decreased by $20 \%$ and so it is much less than in the case of intumescent materials. It is easily explained by the fact that the quantity of polymer is less because it contains the copper wire. For the intumescent materials, the less quantity of polymer cannot explain the huge decrease of THR. It is then assumed that the additional heating inside the materials permits to fasten the intumescent reactions and hence the development of the char. The combustion of the material stops in shorter times and so THR is decreased.

When comparing the evolution of the expansion of the carbon shield obtained by MLC, a relatively low expansion of the carbonaceous layer is observed for the formulation containing $20 \mathrm{wt} \%$ AP760 (Figure 5). For the formulation loaded at 30wt\% of AP760, a much higher expansion than that of the formulation containing 20\%AP760 is observed for the scenario without current. With current, the expansion is strongly reduced. We also note that the conductor is outside the residue. 

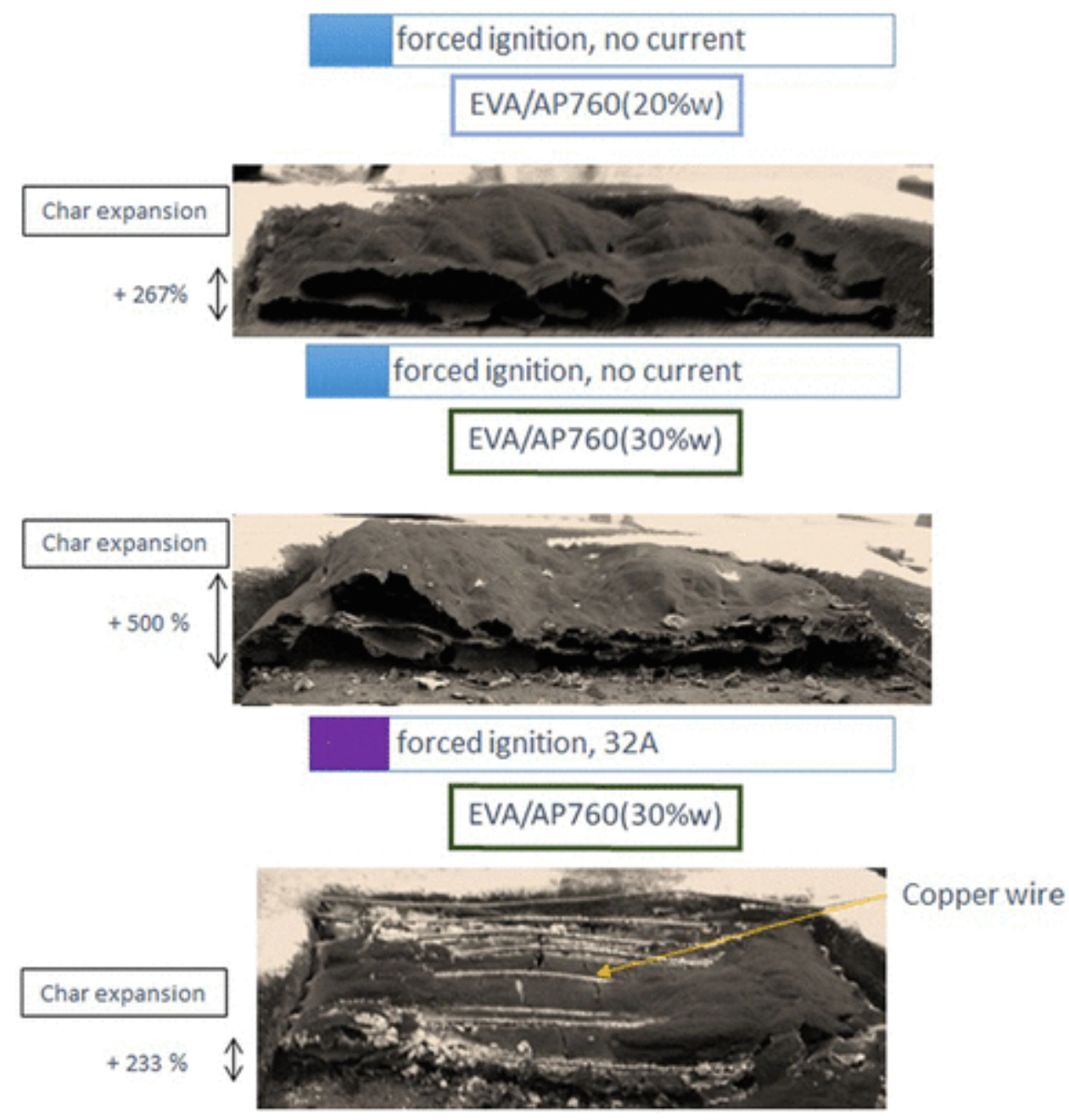

Figure 5.

Residues after MLC experiments with forced ignition for the formulations EVA/AP760 (external heat flux $\left.=35 \mathrm{~kW} / \mathrm{m}^{2}\right)$.

Char's morphology of the above residues is examined by optical microscopy (Figure 6). We can distinguish that the size of the cells depends on the scenario. For formulation at $20 \mathrm{wt} \%$ of AP760, the cells' size is bigger and their number is less than that observed for the formulation containing 30wt\% of AP760 (Table 1). Regarding the formulation containing 30wt\% of AP760, smaller cells are observed for scenario with current. Indeed, the faster intumescent reactions promotes bubbling and hence the apparition of smaller cells. The morphology of the residue obtained for the scenario AP760 20wt\% with electric current is not shown here because we only observe a nonexpanded carbonaceous skin with the copper wire outside of the structure. 


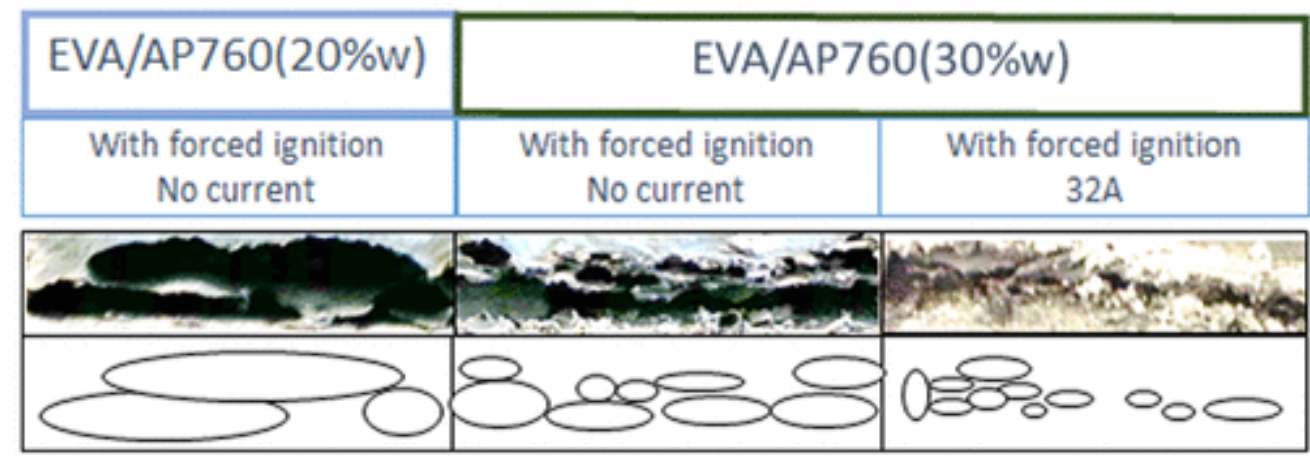

Figure 6.

Char morphology observed after analysis of formulations EVA/AP760 with MLC with forced ignition (external heat flux of $35 \mathrm{~kW} / \mathrm{m}^{2}$ ).

Table I. Cells' size observed after testing the EVA/AP760 formulations at MLC (external heat flux of $\left.35 \mathrm{~kW} / \mathrm{m}^{2}\right)$.

\begin{tabular}{|c|c|c|c|}
\hline & EVA/AP760 (20wt\%) & EVA/AP760 (20wt\%) & EVA/AP760 (30wt\%) \\
\hline & $\begin{array}{l}\text { With forced ignition, } \\
\text { no current }\end{array}$ & $\begin{array}{l}\text { With forced ignition, } \\
\text { no current }\end{array}$ & $\begin{array}{l}\text { With forced } \\
\text { ignition, } 32 \mathrm{~A}\end{array}$ \\
\hline $\begin{array}{l}\text { Dimension max }(\mathrm{mm}) \\
( \pm 0.05 \mathrm{~mm})\end{array}$ & $3.05 \times 0.50$ & $1.60 \times 0.60$ & $0.70 \times 0.20$ \\
\hline $\begin{array}{l}\text { Dimension min }(\mathrm{mm}) \\
( \pm 0.05 \mathrm{~mm})\end{array}$ & $0.80 \times 0.50$ & $0.40 \times 0.30$ & $0.25 \times 0.15$ \\
\hline
\end{tabular}

EVA: ethylene-vinyl acetate; MLC: mass loss calorimeter.

To further investigate the effect of the electric current, the gas phase was examined to characterize the decomposition products according to the MLC fire scenario. The identification of the different gases released by the decomposition of EVA is consistent with the work described in the literature $\underline{13}$ (Figures 7 and $\underline{8}$ ). When applying a heat flux of $35 \mathrm{~kW} / \mathrm{m}^{2}$, the $\mathrm{C}=\mathrm{O}$ stretching in the region around $1810-1790 \mathrm{~cm}^{-1}$ and $\mathrm{OH}$ bending around $998 \mathrm{~cm}^{-1}$ corresponding to acetic acid $\left(\mathrm{CH}_{3} \mathrm{COOH}\right)$, water $\left(\mathrm{H}_{2} \mathrm{O}\right)$ with broad bands around $3900-3500 \mathrm{~cm}^{-1}$, carbon dioxide $\left(\mathrm{CO}_{2}\right)$ corresponding to the absorption bands around $2357-2310 \mathrm{~cm}^{-1}$, carbon monoxide (CO) with absorption bands around $2357-2310 \mathrm{~cm}^{-1}$, methane $\left(\mathrm{CH}_{4}\right)$ with a peak around $3030-990 \mathrm{~cm}^{-1}$, and ethylene $\left(\mathrm{C}_{2} \mathrm{H}_{4}\right)$ with a peak around $995-985 \mathrm{~cm}^{-1}$ was observed. Methane and ethylene come from the scission of the linear polyene formed after the deacetylation of EVA. 

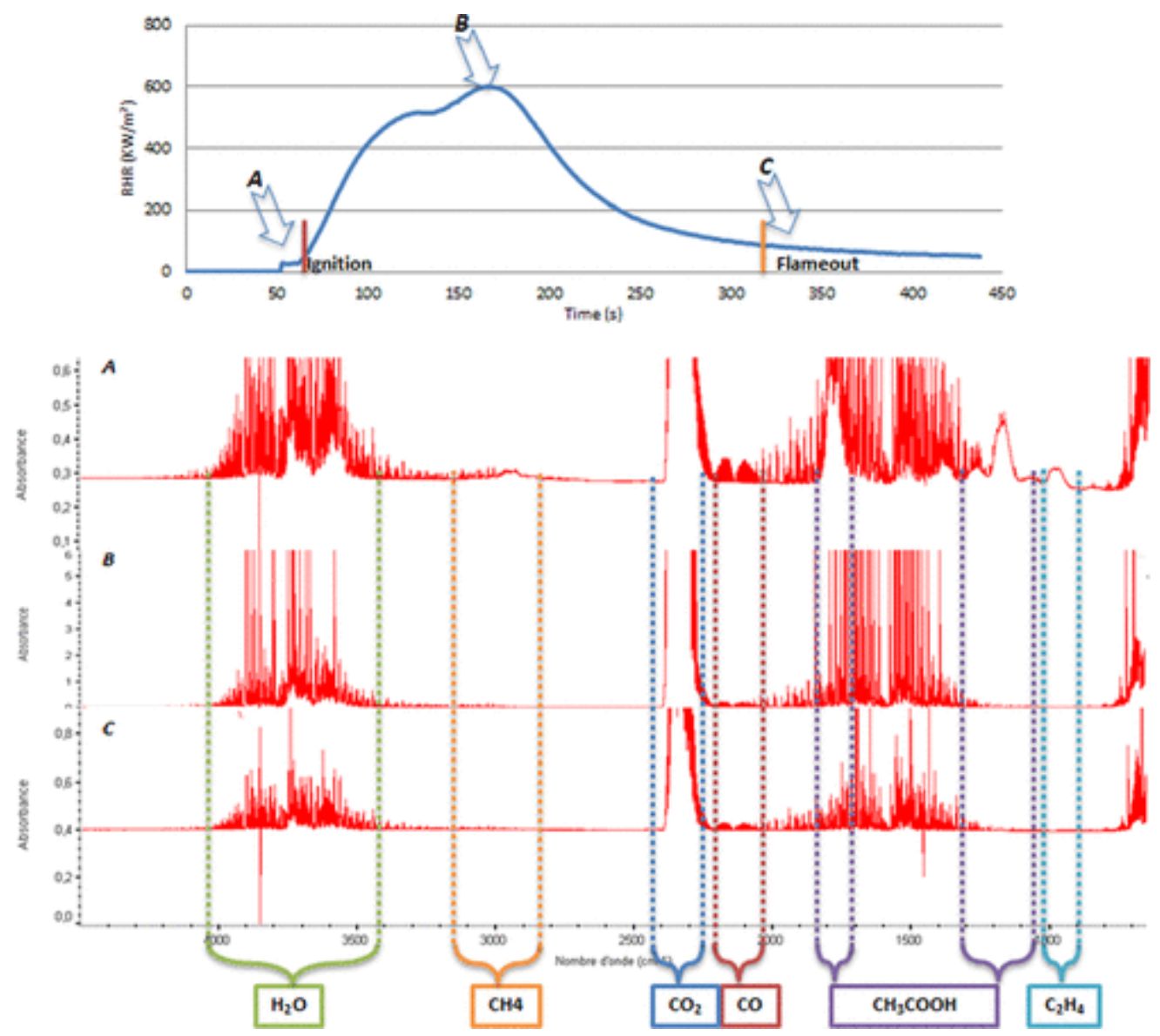

Figure 7.

Evolving gases of combustion of EVA measured by MLC connected to FTIR (without electric current with forced ignition external heat flux $=35 \mathrm{~kW} / \mathrm{m}^{2}$ ). 


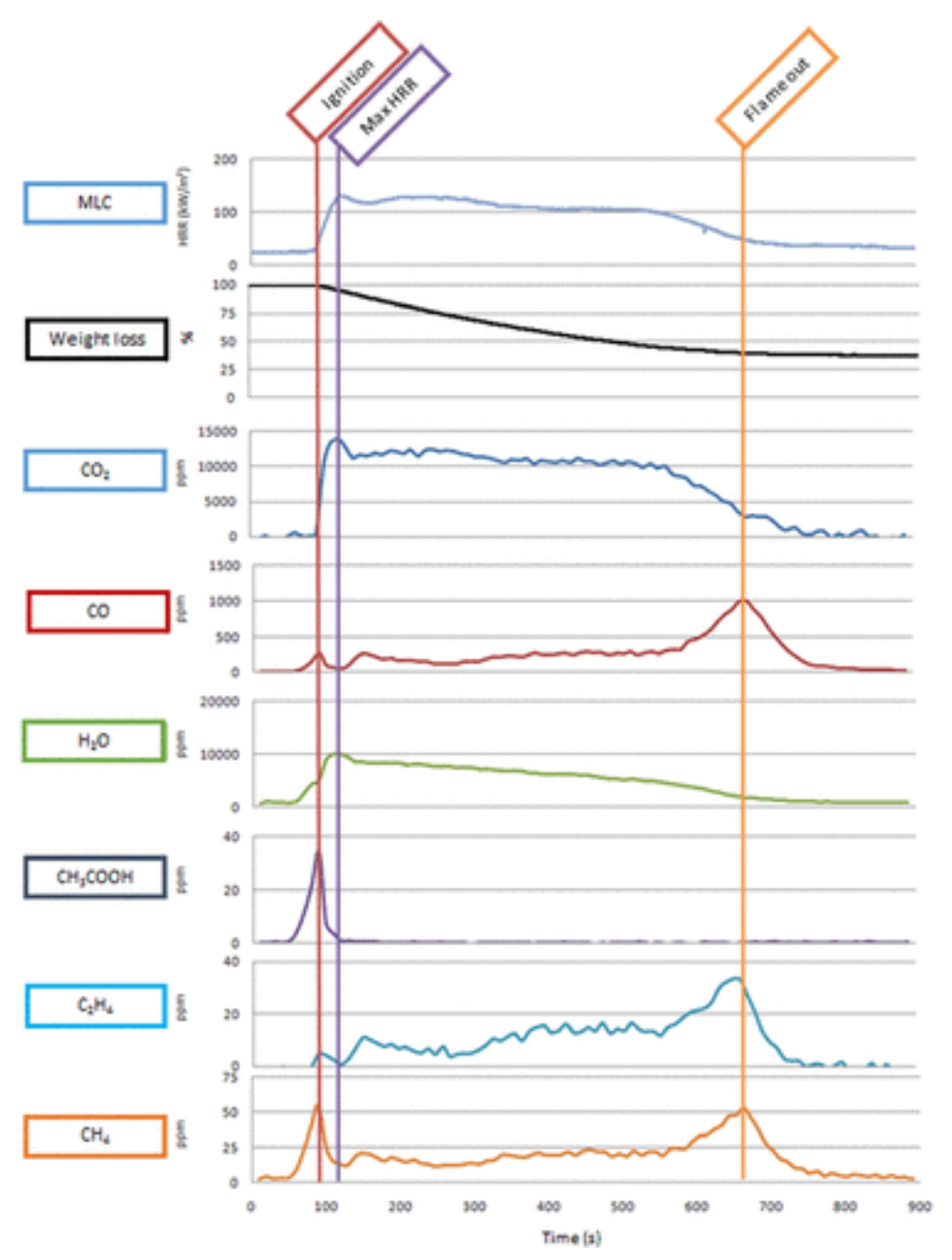

Figure 8 .

Quantification by FTIR of the gases generated by the combustion of EVA (without electric current, external heat flux $=35 \mathrm{~kW} / \mathrm{m}^{2}$ ).

For the EVA-AP760 formulations, acetic acid $\left(\mathrm{CH}_{3} \mathrm{COOH}\right)$, carbon dioxide $\left(\mathrm{CO}_{2}\right)$, carbon monoxide $(\mathrm{CO})$, methane $\left(\mathrm{CH}_{4}\right)$, ethylene $\left(\mathrm{C}_{2} \mathrm{H}_{4}\right)$, and water $\left(\mathrm{H}_{2} \mathrm{O}\right)$ were mainly detected. Additional other gases are also released in lower amount including ammonia $\left(\mathrm{NH}_{3}\right)$ characterized by a peak at $1070 \mathrm{~cm}^{-1}$ and nitric oxide (NO) characterized by a peak at $1900 \mathrm{~cm}^{-1}$ (Figure 9) . 

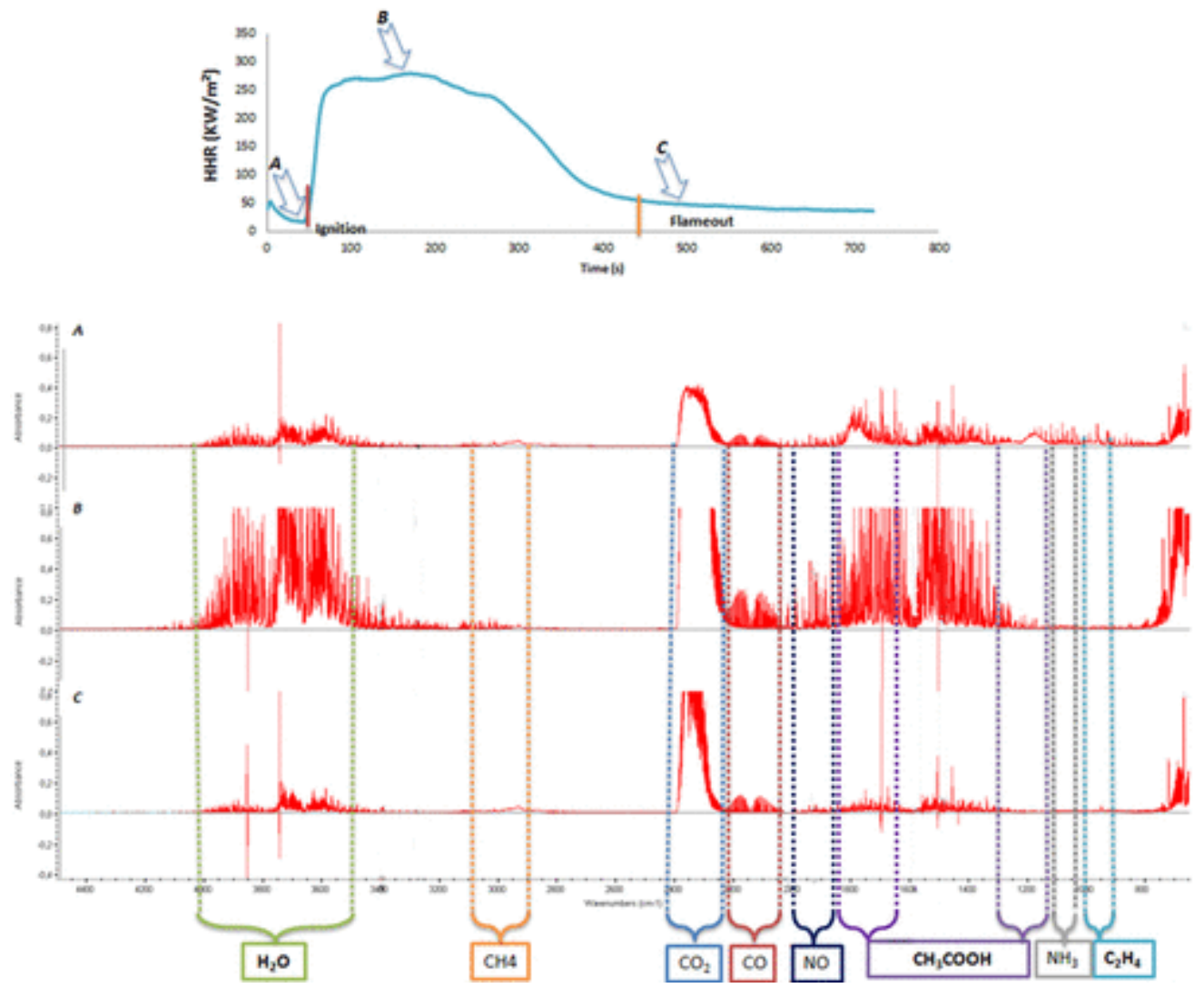

Figure 9.

Evolving gases of combustion of EVA/AP760 measured by MLC connected to FTIR (without electric current with forced ignition external heat flux $=35 \mathrm{~kW} / \mathrm{m}^{2}$ ).

The first step (before ignition) is characterized by the release of $\mathrm{CH}_{3} \mathrm{COOH}, \mathrm{CO}, \mathrm{H}_{2} \mathrm{O}$, and $\mathrm{NH}_{3}$. The evolution of $\mathrm{CH}_{4}$ and $\mathrm{C}_{2} \mathrm{H}_{4}$ is also observed, but the measured concentrations are much lower compared to neat EVA. The thermal degradation of APP takes place releasing water and ammonia: it corresponds to the condensation of APP into ultraphosphate and also to the formation of phoromidic groups. It leads to the release of $\mathrm{NH}_{3}$ and water upon heating and before the ignition (Figure 10). 

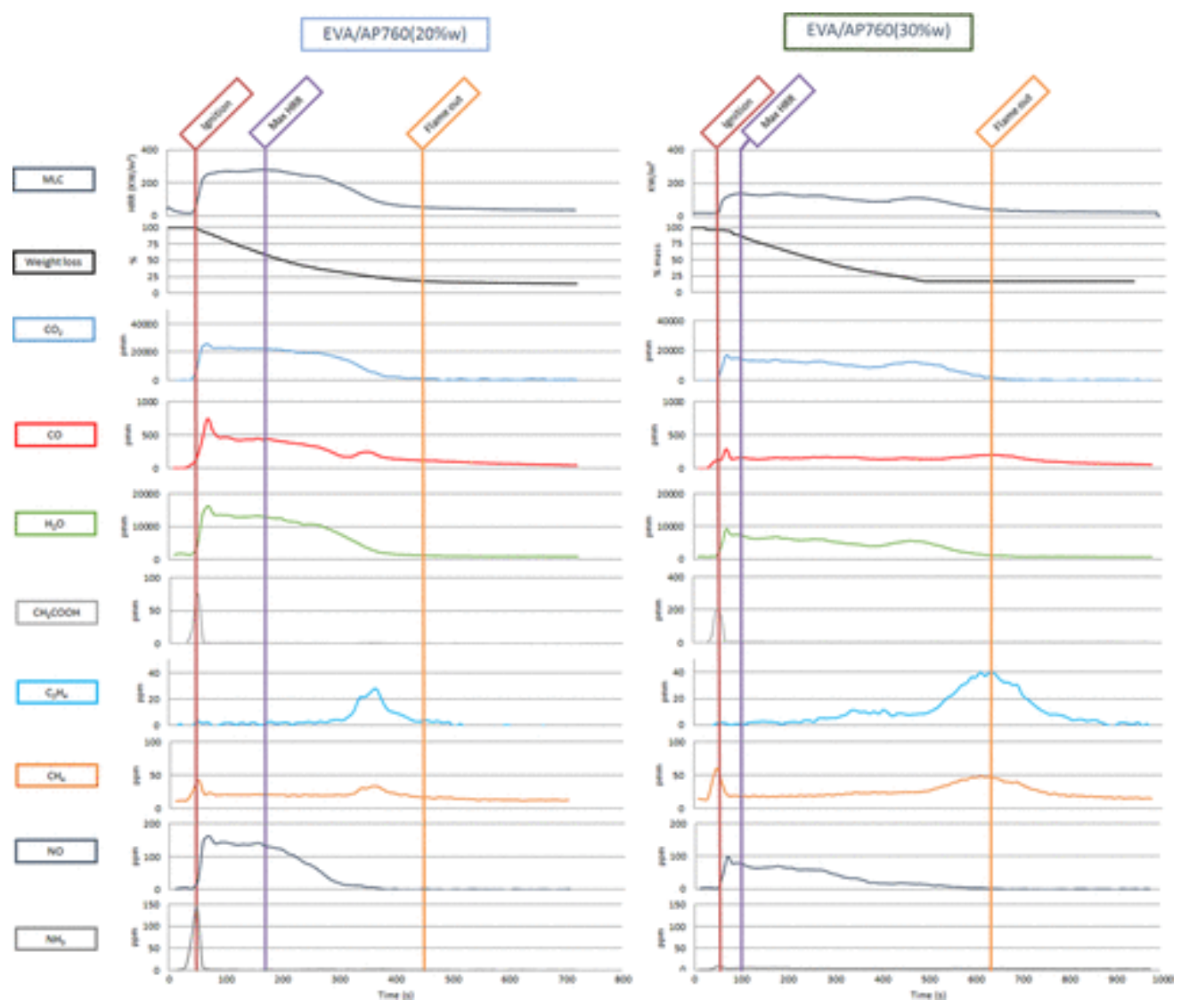

Figure 10.

Quantification of the evolving gases of combustion of EVA/AP760 20wt\% and $30 \mathrm{wt} \%$ measured by MLC connected to FTIR (without electric current external heat flux $=35 \mathrm{~kW} / \mathrm{m}^{2}$ ).

The second step (from ignition to flame out) is characterized by a rapid increase of $\mathrm{CO}_{2}, \mathrm{H}_{2} \mathrm{O}$, and $\mathrm{NO}$ (oxidation of ammonia into $\mathrm{NO}$ ) concentration, while the concentration of $\mathrm{CH}_{3} \mathrm{COOH}$ and $\mathrm{NH}_{3}$ drops down to zero after the ignition. The release of $\mathrm{CO}$ during the flaming process is correlated with the incomplete combustion of hydrocarbons.

The APP acts as an acid source during the pyrolysis of the polymer. A protective layer is formed by the reaction between the polyphosphoric acid and the char former. The protective layer consists of interpenetrated networks of carbon and phosphorous oxides. $\stackrel{14}{\text { According to the }}$

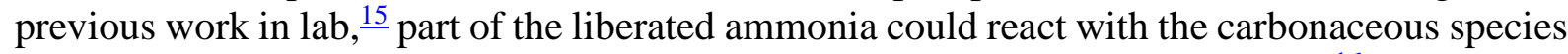
to form nitrogenized aromatic species reinforcing the expanded protective layer. $\underline{16}$

The concentration of ammonia and nitric oxide released depends on the APP concentration and on the scenario (with or without electric current) (Figure 11). To make a comparison, the concentration of the gas was calculated by taking into account the actual weight of the samples (without conductor). Concurrently to the augmentation of the APP content for the scenario without electric current, a significant decrease in the maximum concentration of $\mathrm{NO}$ and $\mathrm{NH}_{3}$ as well as the total amount of NO was observed. For the scenario with electric current, the same trend regarding the maximum concentration of $\mathrm{NO}$ and $\mathrm{NH}_{3}$ was observed. The only difference is that the total amount of $\mathrm{NH}_{3}$ increases significantly when the APP loading increases. Comparing the scenarios with and without electric current, for the formulation containing 13 
20wt $\%$ AP760, an increase in the maximum concentration of NO for the scenario with electric current was observed. For the formulation containing 30wt\% of AP760, NO and $\mathrm{NH}_{3}$ concentrations follow the same trend as for the formulation containing $20 \mathrm{wt} \%$ of AP760. In the scenario with a sample containing the copper wire, when an electric current is applied, a significant increase in the concentration of $\mathrm{NO}$ and $\mathrm{NH}_{3}$ in the gas phase was observed. This increase could be explained both through the heating of the conductor caused by Joule effect which lowers the viscosity of the char and prevents the evolving gases to be trapped in the intumescent structure (low internal pressure making lower expansion of the char) and through the dilation of the copper wire which creates cracks in the intumescent structure, releasing trapped gases.

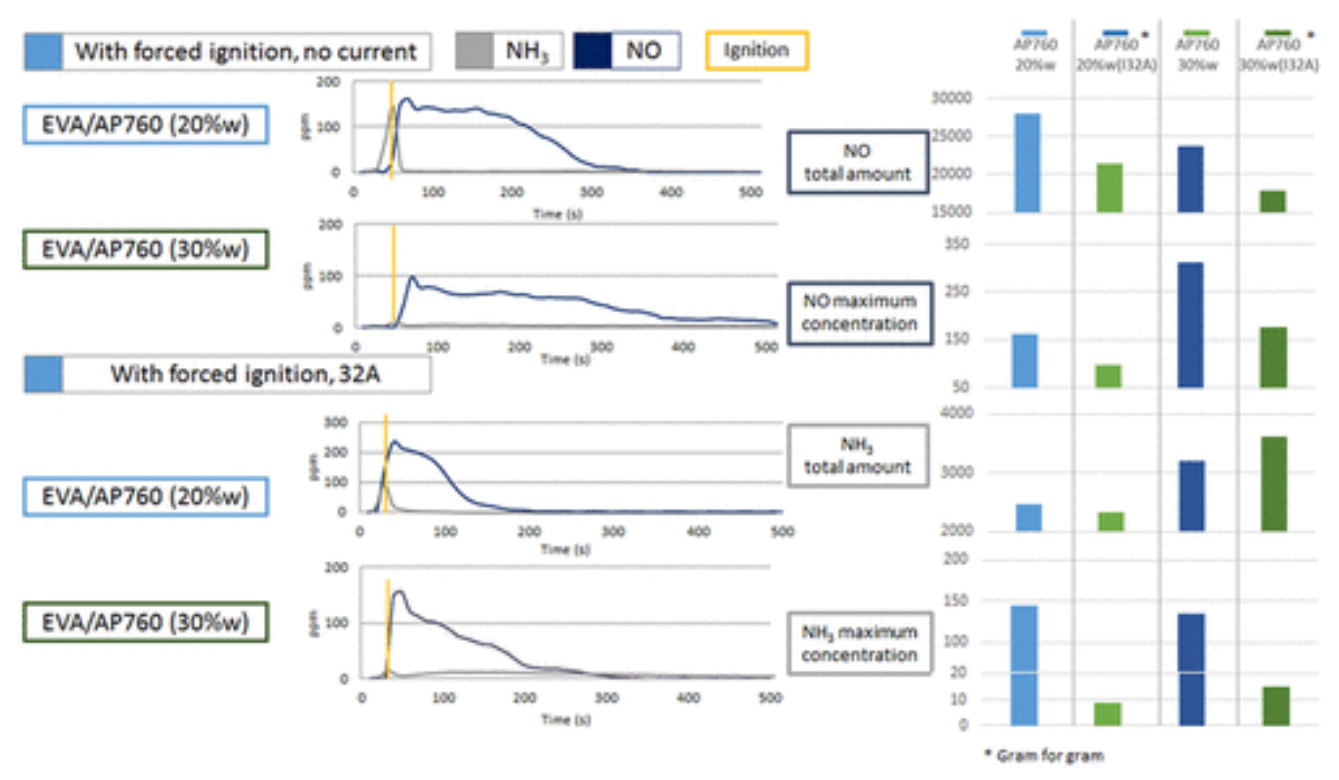

Figure 11.

Evolution of the concentration of $\mathrm{NO}$ and $\mathrm{NH}_{3}$ for the formulation EVA/AP760 (without electric current, with forced ignition external heat flux $\left.=35 \mathrm{~kW} / \mathrm{m}^{2}\right)$.

\section{Flame spread test}

The formulations were first evaluated using the flame spread test developed in our group. Note that the experiments were made in horizontal and vertical positions. An electric current of $32 \mathrm{~A}$ is applied to the conductor to examine the effects of the current on the flame spread.

Four scenarios were investigated by changing the current intensity ( 0 and $32 \mathrm{~A}$ ) and the orientation (horizontal or vertical). The heating due to Joule effect accelerates the material degradation rate and thus increases the flame spread. For the 20wt $\%$ AP760 formulation and in the horizontal scenario, with or without current, the same propagation rate as that of the virgin EVA was observed (Table 2). 
Table 2. Propagation rate for EVA and EVA/AP $76020 \mathrm{wt} \%$ in horizontal position.

\begin{tabular}{lll}
\hline & EVA & EVA/AP760 (20wt\%) \\
\hline Propagation rate $\left(\mathrm{cm} \mathrm{min}^{-1}\right) \mathrm{I}=0 \mathrm{~A}$ & $3.0 \pm 0.5$ & $2.5 \pm 0.4$ \\
Propagation rate $(\mathrm{cm} \mathrm{min}-1) \mathrm{I}=32 \mathrm{~A}$ & $4.9 \pm 0.7$ & $5.0 \pm 0.7$ \\
\hline
\end{tabular}

EVA: ethylene-vinyl acetate.

In vertical position, the dripping of the intumescent formulation (20wt\% AP760) extinguishes rapidly the cable, which makes impossible to measure the propagation rate. Nevertheless, it is noteworthy that the burnt length is higher when current is applied (Figure 12).

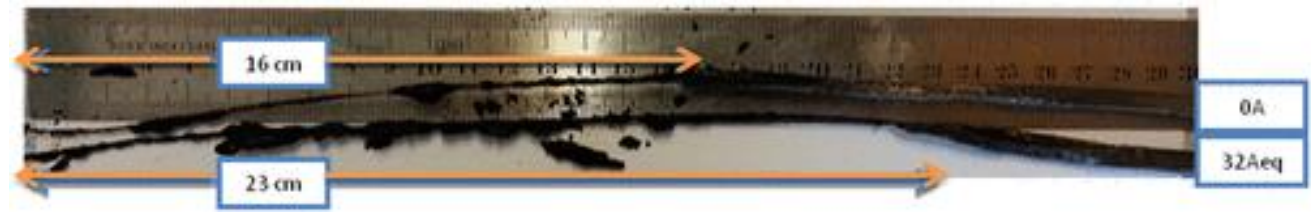

Figure 12.

Residue after flame spread test for EVA/AP $76020 \mathrm{wt} \%$ in vertical position, without and with current.

For the 30wt $\%$ AP760 formulation and for the four scenarios (horizontal and vertical positions, without or with electric current), no flame spread is observed. After the ignition, a char formation at the flame level was observed, but we note, for the scenario with electric current and in horizontal position, the separation of the char from the conductor at the flame level (Figure 13) was observed. The temperature rise caused by Joule effect and by the flame lowers the viscosity of the material which makes it to separate from the conductor.

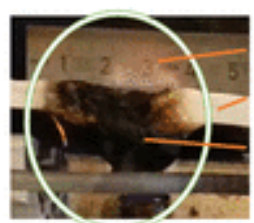

Without current

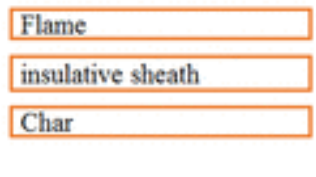

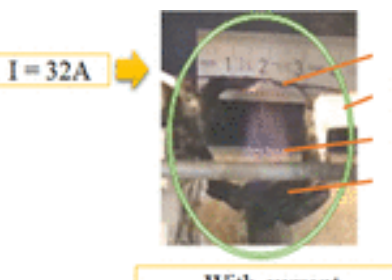

With current

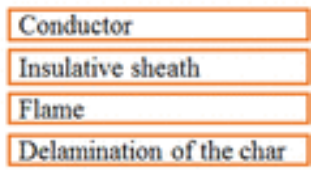

Delamination of the char

\section{Figure 13.}

Residue after the flame spread test for EVA/AP $76030 \mathrm{wt} \%$ in horizontal position.

Using the same setup as above, a high electric current of $60 \mathrm{~A}$ was applied without igniting the sample. The objective is to examine whether the time of delamination can be significantly modified by the composition of the sheathing like in the case of previous works, $\underline{5}$ where it was noted that the incorporation of zinc borate in EVA/ATH blend avoids the delamination. In this case, the AP760-based formulation delaminates from the conductor after the same duration than for neat EVA. So, the heating due to Joule effect provokes the sheath delamination (Table 3 ). 
Table 3. Time to delamination measured at $60 \mathrm{~A}$ according to the flame spread test without open flame in horizontal and vertical positions.

\begin{tabular}{|c|c|c|c|}
\hline Time to delamination (s) & EVA & EVA/AP760 (20wt\%) & EVA/AP760 (30wt\%) \\
\hline $\begin{array}{l}\text { Horizontal position } \\
\text { Vertical position }\end{array}$ & $\begin{array}{l}89 \pm 13 \\
90 \pm 14\end{array}$ & $\begin{array}{l}92 \pm 14 \\
70 \pm 11\end{array}$ & $\begin{array}{r}96 \pm 14 \\
110 \pm 17\end{array}$ \\
\hline
\end{tabular}

EVA: ethylene-vinyl acetate.

\section{Conclusion}

In this work, new protocols and fire tests were developed to characterize the fire behavior of intumescent EVA-based formulations mimicking insulation sheath of electrical cable. Those tests enabled to investigate the role of electric current on the fire behavior of materials. The incorporation of intumescent system significantly improved the fire behavior of the EVA. The electric current causes an additional heating in the material through the copper wire which modifies the fire behavior of the material (MLC and flame spread test). It changes the concentrations of the evolved gases because of this additional heating lowering the viscosity of the intumescent char (limited trapping effect of the gases in the char). At the flame spread test, the additional heating of the conductor caused by Joule effect causes char delamination.

\section{Declaration of conflicting interests}

The author(s) declared no potential conflicts of interest with respect to the research, authorship, and/or publication of this article.

\section{Acknowledgements}

The author(s) disclosed receipt of the following financial support for the research, authorship, and/or publication of this article: This work has received funding from the European Research Council (ERC) under the European Union's H2020 - the Framework program for Research and Innovation (2014-2020)/ERC Grant Advances Agreement no. 670747-ERC 2014 AdG/FireBar-Concept.

\section{References}

1. Hall, JR. Home electrical fires. Quincy, MA: National Fire Protection Association, 2013.

2. Lahoud, N. Modeling aging organic insulation under electrical stress, Application to the reliability of materials. PhD Thesis, 2009, http://hal.archives-ouvertes.fr

3. Novak, CJ, Stoliarov, SI, Keller, MR. An analysis of heat flux induced arc formation in a residential electrical cable. Fire Safe J 2013; 55: 61-68.

4. Auber, R, Atlani, C. Prévention des accidents électriques. Technique de l'ingénieur, Réf D5100VI, http://www.techniques-ingenieur.fr/base-documentaire/archives-th12/archivesreseaux-et-applications-tiadc/archive-1/prevention-des-accidents-electriques-d5100/ 
5. Bourbigot, S, Sarazin, J, Bachelet, P. Small scale evaluation and characterisation of simulated low voltage cables with and without electric current. Fire Mater 2015; 12: 12-22.

6. Delaval, D. Development and intumescent flame retardant system for characterization of polypropylene recycled. $\mathrm{PhD}$ Thesis, 2009, https://ori-nuxeo.univlille1.fr/nuxeo/site/esupversions/393a4921-8908-46b9-848d-d6622b57fe3d

7. Le Bras, M, Bourbigot, S, Camino, G. Fire retardancy of polymers: the use of intumescence. Oxford: Elsevier, 1998, p. 65

8. Louise, C. Speitel, Fourier transform infrared analysis of combustion gases. J Fire Sci 2002; 2: 349-371.

9. Stec, AA, Fardell, P, Blomqvist, P. Quantification of fire gases by FTIR: experimental characterisation of calibration systems. Fire Safe J 2011; 46(5): 225-233.

10. Hakkarainen, T, Mikkola, E, Laperre, J. Smoke gas analysis by Fourier transform infrared spectroscopy—summary of the SAFIR project results. Fire Mater 2000; 24 101-112.

11. Delobel, R, Bourbigot, S, Duquesne, S. Comportement au feu des composites. Technique de l'ingénieur. Réf. AM5330, http://www.techniques-ingenieur.fr/basedocumentaire/materiaux-th11/caracterisation-et-proprietes-d-usage-des-composites42144210/comportement-au-feu-des-composites-am5330/

12. Alongi, J, Han, Z, Bourbigot, S. Intumescence: tradition versus novelty. A comprehensive review. Prog Polym Sci 2015; 51: 28-73.

13. Marcilla, A, Gomez, A, Menargues, S. TG/FTIR study of the thermal pyrolysis of EVA copolymers. J Anal Appl Pyrolysis 2005; 74: 224-230.

14. http://www.flameretardants-online.com/web/en/106/109.htm, 2015

15. Delobel, R, Bourbigot, S, Le Bras, M. Invariant values of kinetic parametersevaluation of fire retardancy application to the PP-APP/PER system. Macromol Symp 74: 5969.

16. Bourbigot, S, Le Bras, M, Delobel, R. Synergistic effect of zeolite in an intumescence process: study of the carbonaceous structures using solid state NMR. J Chem Soc Farad Trans 92: 149-158. 